\title{
Biostatistics course in postmaster doctor of nursing practice programs
}

\author{
Aliya Kuerban * \\ Molloy College, New York, United States
}

Received: August 4, 2016

DOI: $10.5430 /$ jnep.v7n3p26
Accepted: October 20, $2016 \quad$ Online Published: October 27, 2016

URL: http://dx.doi.org/10.5430/jnep.v7n3p26

\begin{abstract}
Background: The number of doctor of nursing practice (DNP) programs in the United States has increased dramatically in the past few years. However, few studies have been done to provide a comprehensive view of program structures and curricula offered.

Methods: This study explored differences in entry pathway, admission statistics skills requirement, and whether a program offered a Biostatistics course in its curriculum by investigating the websites of DNP programs listed on the American Association of Colleges of Nursing (AACN) DNP directory.

Results and conclusions: This study found no regional differences in these three areas: type of program offered, statistics course as a prerequisite, and whether Biostatistics is offered. Overall, more schools have started to require a graduate level statistic course in their admission requirement and more schools offered a Biostatistics course in their DNP curriculum. However, $25 \%$ of schools did not request for specific statistics skills prior to admission, nor did they incorporate a Biostatistics course in the program.
\end{abstract}

Key Words: Doctor of nursing practice, Biostatistics, Prerequisite

\section{INTRODUCTION}

Since the American Association of Colleges of Nursing (AACN) published its position paper regarding the need for the nursing profession to develop a new practice focused terminal degree for advanced nurse practitioners in 2004, the doctor of nursing practice (DNP) programs have grown in great number from the original 20 programs in 2006 to more than 240 programs in 2013. ${ }^{[1]}$ At the time of this research, there were 264 programs listed on the DNP program directory at AACN's website. The enrollment of these programs increased dramatically. In 2006, there were 862 students enrolled in DNP programs; however, in 2013, the enrollment reached $14,699,{ }^{[1]}$ a growth of more than 17 times. This growth was facilitated by the publication of The Essentials of Doctoral Education for Advanced Nursing Practice
(Essentials) $^{[2]}$ and The DNP Roadmap Task Force Report (Roadmap) by the AACN in October 2006. ${ }^{[3]}$ The above publications outlined a workable framework for the DNP entry pathway, curriculum, and competencies. The development of a practice doctorate was also supported in the National Research Council's report titled Advancing the Nation's Health Needs: NIH Research Training Programs. ${ }^{[4]}$

Although there were two possible entry pathways of DNP programs, bachelor of science in nursing to DNP (BSNDNP) and master of science in nursing to DNP (MSN-DNP), MSN-DNP was still the predominant entry path, and such programs enroll about two times more students than their BSN-DNP counterpart. ${ }^{[1]}$ Due to the high demand of MSNDNP route, most of the schools who adopted the BSN-DNP entry pathway still retained their postmaster option to DNP

*Correspondence: Flávio L. C. Pádua; Email: akuerban@molloy.edu; Address: Molloy College, New York, United States. 
programs. ${ }^{[1]}$

The Essentials provided by the AACN serves as the guide for programs leaders throughout the nation to develop their curricula. In the Essentials, Essential III, IV, and VII described the importance of biostatistics courses as an integrated part of DNP curriculum to prepare DNP graduates with the skills they need. Since the program focus of DNP was specifically on the practice aspect, the courses offered should be fundamentally different from the traditional research oriented doctor of philosophy degree $(\mathrm{PhD})$ program. The Essentials did not specify the exact courses and the sequence an institution was required to adopt. Each school is responsible in designing its own curriculum based on the recommendations specified in the Essentials, which inevitably creates variations in the interpretations of the method of delivery.

The course of Biostatistics is not only a critical component of the Essentials, but also a core element of evidence-based practice. It sets the foundation for information synthesis, data interpretation, appraisal of existing research outcomes, and evaluation of the implementation of newly produced knowledge. Although statistics in nursing education is important, a panel of statistics experts who actively teach, consult, and collaborate in the academic nursing field noted "ironically... little is known about the state of the science of statistics education in the nursing field. For example, no known publications describe the amount and level of statistics training offered in nursing schools. ${ }^{[5] \text { ", }}$

A survey on medical professionals, such as medical students, internal medicine residents, and internal medicine teaching faculty at Mayo Clinic College of Medicine in Rochester, Minnesota, found clinicians from all levels of training felt they did not have enough knowledge in biostatistical concepts, although they all recognized the importance of this knowledge in their practice. ${ }^{[6]}$ A program evaluation on giving continuing education courses to public health and mental health professionals found that basic biostatistics and epidemiology were the courses demanded the most. ${ }^{[7]}$

The above studies indicated the self-awareness of an insufficiency of quantitative data analysis skills among clinicians. According to the Essentials, the DNP curriculum should adequately prepare graduates in analyzing data and predict outcomes to fill the gaps between original research and evidencebased practice. ${ }^{[2]}$ The competence in translating research requires future healthcare leaders to be proficient in using data to make programmatic decisions.

\section{Purpose}

There is a lack of systematic analysis on how the Biostatistics course is offered in DNP programs in the United States. Two

Published by Sciedu Press pioneer studies completed in 2012 provided benchmark data regarding DNP program attributes and admission criteria. ${ }^{[8,9]}$ However, both studies were done a few years ago and the DNP programs have increased from 137 to 264 at the time of this study. New and current benchmark data is needed and a closer look at a specific course of DNP curriculum, such as Biostatistics, is also important in helping schools design, redesign, evaluate, and improve their DNP programs. This study provided a contextual analysis of DNP programs by investigating the regional differences in the implementation of teaching biostatistics at graduate level, which is valuable for the evidence-based improvement of the quality of DNP programs. This study is the first study to present aggregate data on the topic of statistics course offered at the DNP level national wide, which was a data gap identified by experts in teaching statistics to nursing students. ${ }^{[5,10]}$

\section{METHOD}

Quantitative content analysis of DNP programs' curriculum and admission criteria posted on schools' websites was conducted. No information was gathered through other methods, such as telephone interviews or emails. Collecting information only through the content analysis of the websites reduced the bias created by the inconsistency of the responses provided by different individuals who answered the request.

When looking at the Biostatistics course, this study emphasized the programs offering the course at a graduate level. Concerning schools with both BSN-DNP and MSN-DNP tracks, information regarding graduate level Biostatistics as a prerequisite, and whether Biostatistics was offered as an individual course in the curriculum plan were collected only from the MSN-DNP track of the program.

\subsection{Sample}

The AACN DNP website maintains a current list of DNP programs in the United States, which served as the sampling frame of this study. Previous studies had also used the same sampling frame with reliable results. ${ }^{[8,9,11]}$ At the time of this study (July 2015), according to the AACN's website, there were 264 schools listed providing DNP programs. All schools were categorized into four regions based on the census regions defined by the United States Census Bureau: ${ }^{[12]}$ West, Midwest, South, and Northeast. At the time of this study, there are 38 schools from the West region (Arizona, California, Colorado, Idaho, Montana, Nevada, New Mexico, Oregon, Utah, Washington, and Wyoming), 77 schools from the Midwest region (Illinois, Indiana, Iowa, Kansas, Michigan, Minnesota, Missouri, Nebraska, North Dakota, Ohio, South Dakota, and Wisconsin), 91 schools from the South region (Alabama, Arkansas, Delaware, District of Columbia, 
Florida, Georgia, Kentucky, Louisiana, Maryland, Missis- due to the lack of detailed curriculum information. sippi, North Carolina, Oklahoma, South Carolina, Tennessee, Texas, Virginia, and West Virginia), and 58 schools from the Northeast region (Connecticut, Maine, Massachusetts, New Hampshire, New Jersey, New York, Pennsylvania, Rhode Island, and Vermont).

Among the 264 schools studied, nine schools did not have sufficient information listed to indicate the exact type of programs they offered and therefore were eliminated. Twentyfour schools did not have enough information in their admission requirement section to specify whether they had a graduate level statistics as a prerequisite for graduate admission and therefore were not included in the data presented in Figure 1. Forty-four schools were eliminated from Figure 2

\subsection{Variables}

The following information was extracted from the individual program's website: type of program the school offered, whether a graduate level statistics course was a prerequisite for the MSN-DNP track, and whether a Biostatistics course or biostatistics related course was offered as an individual course listed in the curriculum plan. Any course with the indication of the inclusion of quantitative data analysis was considered as a biostatistics related course as in the instance of quantitative methods for evaluating health care practice, clinical data management and analysis, and analytical methods for evidence based practice (see Table 1).

Table 1. List of different quantitative analysis courses evaluated as Biostatistics course

\begin{tabular}{|c|c|}
\hline Advanced biostatistics and research design & Biostatistics for advanced practice in health care \\
\hline Advanced data analysis I and II & Biostatistics for APN \\
\hline Advanced epidemiology and biostatistics & Biostatistics for clinical practice \\
\hline Advanced epidemiology and biostatistics for population health & Biostatistics for evidence based practice \\
\hline Advanced health care statistics & Biostatistics for healthcare professionals \\
\hline Advanced health care statistics I & Biostatistics for outcomes evaluation \\
\hline Advanced statistical analysis & Biostatistics for outcomes management and evaluation \\
\hline Advanced statistics & Biostatistics for the advanced health practitioner \\
\hline Advanced statistics for clinical practice & Clinical data management and analysis \\
\hline Advanced statistics: multivariate analysis & Comparative quantitative research design and methodology \\
\hline Analytical methods for evidence-based clinical practice & Data analysis II \\
\hline Analytical methods for evidence-based practice & Design and statistical methods for advanced nursing practice \\
\hline Applied biostatistics & EBP methods and techniques \\
\hline Applied biostatistics for outcomes evaluation & Educational statistics and data processing \\
\hline Applied biostatistics in clinical research & Epidemiology and Biostatistics \\
\hline Applied data analysis & Graduate statistics for advanced practice and research \\
\hline Applied epidemiology and biostatistics & Health statistics and another course advanced statistics \\
\hline Applied statistical analysis for health care research I & Inferential statistics \\
\hline Applied statistical analysis I & Integration of healthcare research \& statistics \\
\hline Applied statistical methods for practice inquiry & Intermediate biostatistics \\
\hline Applied statistics & Stat theory \& comp. application I \\
\hline Applied statistics for evidence based practice & Intermediate stats for translational nursing research \\
\hline Applied statistics for health professions & Introduction to biostatistics \\
\hline Applied Statistics for the health sciences & Management of health data \\
\hline Biostatistical methods for evidence based practice & Meeting population demands through biostatistics \\
\hline Biostatistics and epidemiological supports for health service & Multivariate Analysis \\
\hline development & Nursing Statistics \\
\hline Biostatistics and epidemiology & Practical application of statistics in healthcare \\
\hline Biostatistics and epidemiology for advanced practice nurses & Principles of epidemiology and biostatistics \\
\hline Biostatistics and epidemiology for clinical practice & Qualitative methods and biostatistics \\
\hline
\end{tabular}

\subsection{Analysis}

Analyses was conducted with SPSS version 22.0. Four bivariate cross-tabulations were produced for the exploration of regional differences. Chi-square testing was performed for each bivariate relationship. An odds ratio analysis was performed to discover the chance for a program to offer Biostatistics to DNP students when the program did not request for a graduate level statistics course as a prerequisite. 


\section{RESUltS}

Figure 3 shows the type of program by region. At the time of the study, only just five schools (2\%) did not offer any other tracks except offered only BSN-DNP; the rest of the schools all offered MSN-DNP track to their prospective students. Among the schools offering MSN-DNP tracks, half of them also provided BSN-DNP track as an option. Schools from the Northeast had a highest percentage of offering MSN-DNP track (57.9\%); schools from the South region had the lowest percentage of offering MSN-DNP track (44.3\%).

Among schools with MSN-DNP track, $68.8 \%$ of them did not require a graduate level statistics course as a prerequisite for admission (see Figure 1). Schools from the Northeast region $(41.5 \%)$ were more likely than schools from other regions to require students to take a graduate level statistics course prior to admission. Schools from the South region were the least likely $(23.8 \%)$ to request a graduate level statistics course as a prerequisite.

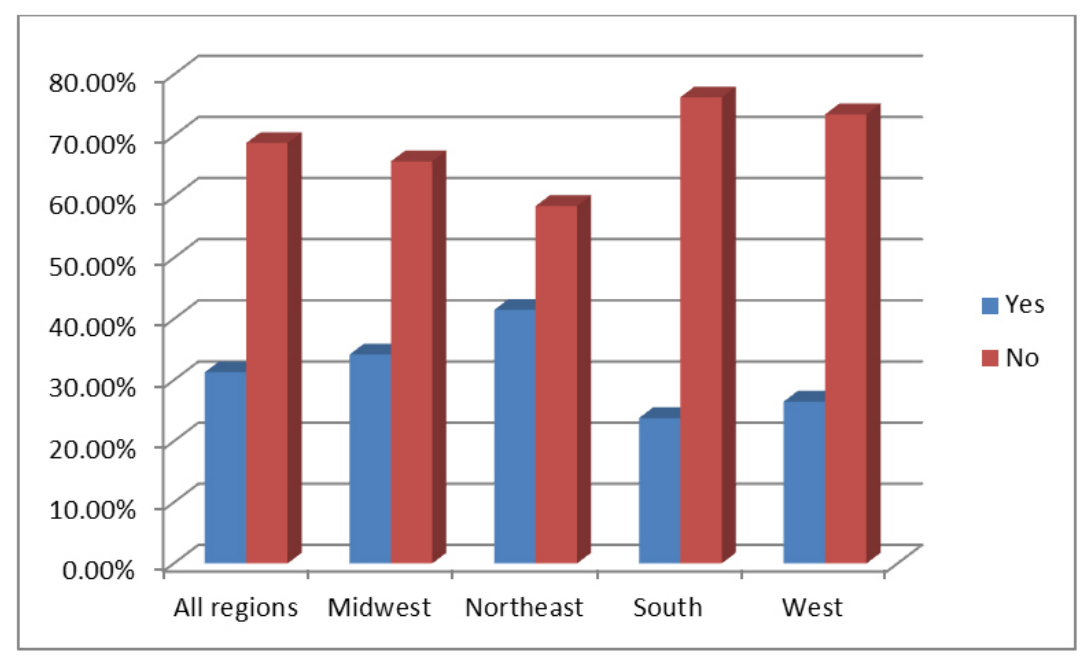

Figure 1. Statistics as a prerequisite by region

Throughout the country, there were more schools that offered a Biostatistics course than schools that did not (see Figure 2). Again, schools from the Northeast region had the highest percentage $(69.2 \%)$ of programs offering a Biostatistics course to their students compared with schools from other regions. Schools from the Midwest region were least likely to offer Biostatistics course.

Chi-square analysis was carried out and revealed that there was no significant association between region and type of program offered (Chi-square 3.632, $p=.726$ ), region and statistics as a prerequisite (Chi-square 5.358, $p=.147$ ), and region and Biostatistics offered (Chi-square 4.308, $p=.230$ ).

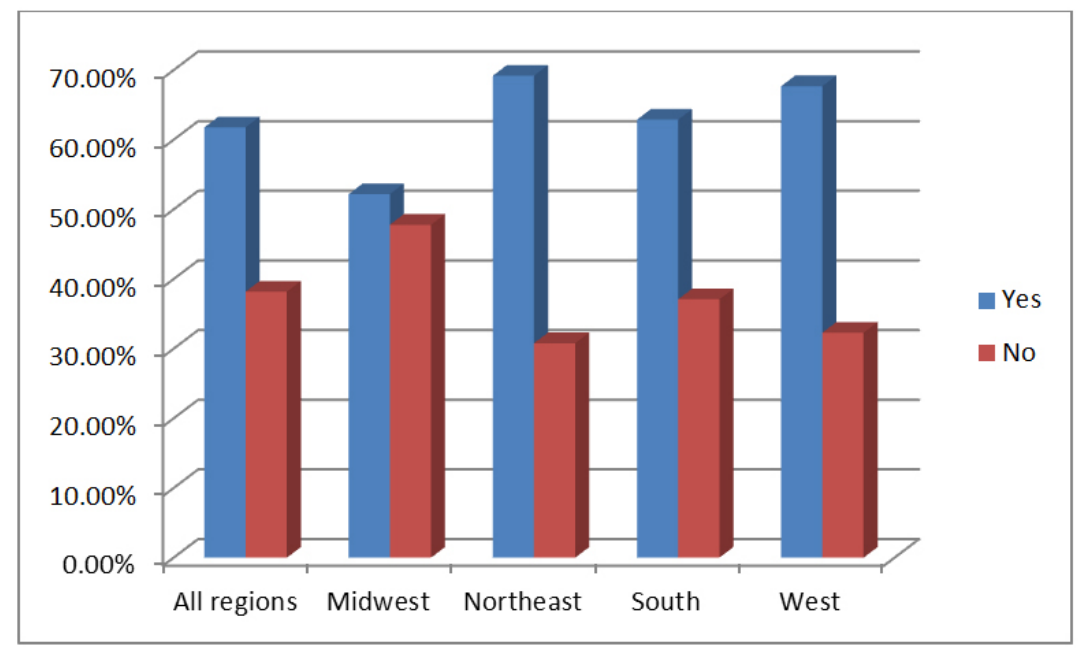

Figure 2. Biostatistics course offered by region 


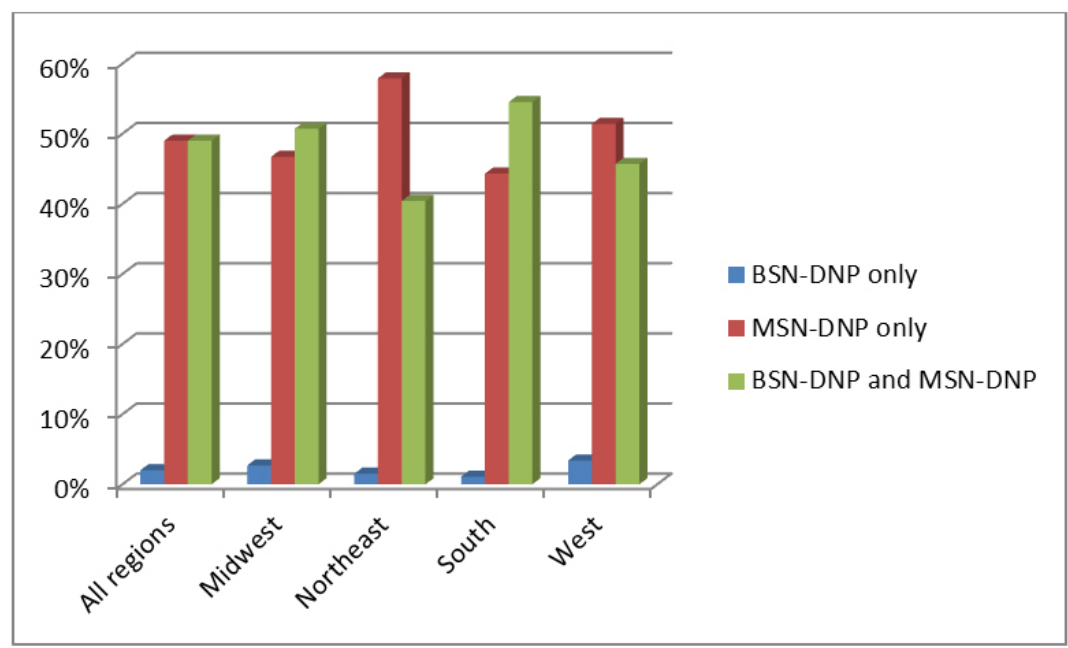

Figure 3. Type of program by region

Table 2 indicates that 37 out of $220(17 \%)$ programs required students to take a graduate level statistics course prior to admission, and the program also offered a Biostatistics course in the MSN-DNP curriculum. On the contrary, 54 programs (25\%) not only did not have a graduate level statistics course as a prerequisite, but also did not have Biostatistics in their DNP curriculum.

Table 2. Graduate level statistic course as a prerequisite by Offering Biostatistics course

\begin{tabular}{lll}
\hline \multirow{2}{*}{$\begin{array}{l}\text { Graduate level statistics } \\
\text { as a prerequisite }\end{array}$} & \multicolumn{2}{l}{ Offering Biostatistics } \\
\cline { 2 - 3 } Yes f (\%) & No f (\%) \\
\hline Yes & $37(28)$ & $30(35.7)$ \\
No & $95(72)$ & $54(64.3)$ \\
Total & 132 & 84 \\
\hline
\end{tabular}

Odds ratio was calculated based on the data indicated in Table 2. The odds of offering Biostatistics class were 1.15 (CI 0.902-1.478) times more likely among the schools that did not require graduate level statistics as a prerequisite than those that did have the requirement.

\section{Discussion AND CONCLUSION}

No statistically significant regional differences in type of program offered, statistics as a prerequisite, and Biostatistics offered were found in the bivariate relationships. This lack of regional differences reflected a uniform presentation of above benchmarks throughout the country. Regardless the origin of the schools, they all moved toward the direction led by both the Essentials and the Roadmap in a coherent manner. Given the newness of this degree program, the even development of DNP curriculum was positive. This lack of regional differences could also further ensure a more reliable and consistent overall student learning outcome.

Compared with previous study, ${ }^{[9]}$ more schools started to provide the option of BSN-DNP track, an increase from 59 schools $^{[9]}$ to 125 schools in three years (at the time of this study). The momentum of this transition is clearly evidenced. The direct pathway from BSN to DNP, eliminating the middle step of MSN, enables schools to implement more vigorous curricula for the students and train them with a higher standard toward the ultimate goal of completing a DNP degree.

The core purpose of the DNP program is to prepare students to be able to translate existing research into practice. Beyond graduate level quantitative analysis skill is critical for DNP students to master. Although compared with three years ago, the percentage of schools requiring students to take graduate level statistics course before admission to DNP program increased from $19.9 \%{ }^{[9]}$ to $31.3 \%$ at the time of this study; the majority of the schools (69.0\%) still do not have the specific requirement regarding statistic skills on admission.

According to the odds ratio analysis, schools that did not request graduate level statistics as a prerequisite were more likely to offer Biostatistics course to their DNP students. However, the finding might not be meaningful as the odds ratio included 1. It is possible schools that do not require a graduate level statistic course as a prerequisite for incoming graduate students might make extra effort to equip students with statistics skills through offering their own Biostatistics course; $44 \%$ of schools did fit into the above description. However, there were still 54 schools that did not do both. In other words, $25 \%$ of the schools not only did not request their students to take a graduate level statistics course prior to admission, nor did they offer a Biostatistics course in the 
curriculum.

A prerequisite course itself can add an additional burden to students. Students might have to spend extra money and time to meet the requirement before they apply for the program. At the same time, there is no clear evidence to support better outcomes for those who have completed a statistic course prior to admission than those who have not. ${ }^{[13]} \mathrm{A}$ general statistics course without emphasizing practical application and translation analysis might not be relevant to DNP students. Therefore, schools might start to loosen the requirement for a graduate level statistics course as a prerequisite for their DNP students. However, schools must be creative in weaving quantitative analysis skills into their curricula to meet the requirements listed in the Essentials by AACN if they do not offer a separate Biostatistics course.
Experts involving in statistics education and consulting in nursing programs recommended DNP degree programs to offer their students a course focusing on statistical literacy and reasoning. ${ }^{[5,14]}$

This study is limited to the information collected through content analysis of DNP programs' websites. Details such as whether the program imbedded the skills taught in the course of Biostatistics into courses named implicitly were not reflected in this study. Meanwhile, this study also did not include the programs not having their curriculum available online, which was an inevitable bias of the sampling method chosen.

\section{CONFlicts OF INTEREST Disclosure}

The author declares that there is no conflict of interest.

\section{REFERENCES}

[1] Auerbach DI, Martsolf G, Pearson ML, et al. The DNP by 2015: A study of the institutional, political, and professional issues that facilitate or impede establishing a post-baccalaureate doctor of nursing practice program. 2014. Available from: http://www . aacn.nche. edu/dnp/DNP-Study.pdf

[2] American Association of Colleges of Nursing. The essentials of doctoral education for advanced nursing practice. 2006a. Available from: http://www. aacn.nche.edu/dnp/pdf/Essentials.pdf

[3] American Association of Colleges of Nursing. DNP roadmap task force report. 2006b. Available from: http://www. aacn.nche.ed $\mathrm{u} / \mathrm{dnp} / \mathrm{pdf} /$ DNProadmapreport.pdf

[4] National Research Council. Advancing the nation's health needs. 2005. Available from: https://grants.nih.gov/training/na s_report_2005.pdf

[5] Hayat MJ, Eckardt P, Higgins M, et al. Teaching statistics to nursing students: an expert panel consensus. Journal of Nursing Education. 2013; 52(6): 330-334. PMid:23621121 http://dx.doi.org/10. 3928/01484834-20130430-01

[6] West CP, Ficalora RD. Clinician attitudes toward biostatistics. Mayo Clinic Proceedings. 2007; 82(8): 939-943. PMid:17673062 http: //dx.doi.org/10.4065/82.8.939

[7] Beebe LA, Neas BR, Asal NR. The health agency training program: Continuing education courses in biostatistics and epidemiology. Public Health Reports. 2000; 115(4): 370-377. http://dx.doi .org/1 $0.1093 / \mathrm{phr} / 115.4 .370$

[8] Mancuso JM, Udlis KA. Doctor of nursing practice programs across the United States: A benchmark of information: Part II: Admis- sion criteria. Journal of Professional Nursing. 2012; 28(5): $274-$ 283. PMid:23006649 http://dx.doi.org/10.1016/j.profnur s.2012.01.002

[9] Udlis KA, Mancuso JM. Doctor of nursing practice programs across the United States: A benchmark of information: Part I: Program characteristics. Journal of Professional Nursing. 2012; 28(5): 265273. PMid:23006648 http://dx.doi.org/10.1016/j.profnur s. 2012.01 .003

[10] Hayat MJ, Schmiege S, Cook PF. Perspectives on statistics education: observations from statistical consulting in an academic nursing environment. Journal of Nursing Education. 2014; 53(4): 185-191. PMid:24641080 http://dx.doi .org/10.3928/01484834-201 40321-01

[11] Fulton CR, Meek JA, Walker PH. Faculty and organizational characteristics associated with informatics/health information technology adoption in DNP programs. Journal of Professional Nursing. 2014; 30(4): 292-299. PMid:25150414 http://dx.doi.org/10.1016 $/ j$.profnurs.2014.01.004

[12] United States Census Bureau. Regions and Divisions. 2015. Available from: https://www. census.gov/econ/census/help/geogra phy/regions_and_divisions.html?cssp=SERP

[13] Grace JT, D'Aoust, R. Evidence-based program requirements evaluation of statistics as a required course. Nursing Education Perspectives. 2006; 27(1): 28-33.

[14] Hayat, M. J. Guidelines for assessment and instruction in statistics education (GAISE): extending GAISE into nursing education. Journal of Nursing Education. 2014; 53(4): 193-198. 